\title{
Classification and Pixel-Based Segmentation to Evaluate Soybean Seeds Submitted to Tetrazolium Test
}

\author{
Davi Marcondes Rocha ${ }^{1}$, Lúcia Helena Pereira Nóbrega ${ }^{2}$, Maria de Fátima Zorato ${ }^{3}$, \\ Vitor Alex Alves de Marchi ${ }^{1} \&$ Arlete Teresinha Beuren ${ }^{1}$ \\ ${ }^{1}$ Computer Science Department, Federal University of Technology-Paraná, Santa Helena, Paraná, Brazil \\ ${ }^{2}$ Tec. and Exact Sciences Center, Western Paraná State University, Cascavel, Paraná, Brazil \\ ${ }^{3}$ Biologist, Seed Science \& Technology, Londrina, Paraná, Brazil \\ Correspondence: Davi Marcondes Rocha, Computer Science Department, Federal University of \\ Technology-Paraná, Santa Helena, Paraná, Brazil. E-mail: davimarcondesrocha@gmail.com
}

Received: April 25, 2019

doi:10.5539/jas.v11n13p186
Accepted: June 3, 2019 Online Published: August 15, 2019

URL: https://doi.org/10.5539/jas.v11n13p186

\begin{abstract}
Production and use of high quality seeds are essential for the soybean crop. Thus, the quality control system in seeds industry must be reliable, precise, and fast. Tetrazolium test evaluates not only seeds viability but also their vigor, as well as provides information concerning agents that cause their quality reduction. Although this test does not use expensive devices and reagents, it requires a well-trained analyst. Its precision depends on knowledge of all techniques and required procedures. Besides, also necessary is the observer's subjectivity. So, this trial aimed at developing a computational tool that could minimize the implicit subjectivity in carrying out this test. It also contributes to generate a greater credibility of information and to guarantee precise answers. Algorithms of supervised classification were applied based on extraction of digital images characterization of tetrazolium test. This procedure aimed at producing pixel-based segmentation of those images, to produce a digital segmented image of tetrazolium test according to damage classes. This tool allows, based on image of tetrazolium test, to identify damage on soybean embryos, as well as its site and extension on tissues, so that the interpretation is less subjective. The applied method allowed identifying damage on images of tetrazolium tests in a straightforward way, as well as extracting safer information about those damages and carrying out management control of tetrazolium test according to a seed data file.
\end{abstract}

Keywords: machine learning, patterns recognition, seeds vigor

\section{Introduction}

Soybean crop has much contributed to the Brazilian commercial agriculture. It helped on crop mechanization speed, as well as it modernized transportation, expanded agricultural boundaries, and has taken part in the technological evolution and in another crops production. It also helped the development of Brazilian poultry and swine farming (Dall'Gnol, 2000). Its high protein content (40\%) is considered a raw material to feed domestic animals, and although it does not have a high oil content (about 20\%), soybean and palm are the greatest oil producers (Roessing, Dall'Agnol, Lazzarotto, Hirakuri, \& Oliveira, 2007).

According to Marcos-Filho (2015), seed technology has as main objective the development of efficient mechanisms for the productive chain, using high-quality batches. Quality seeds are those that contain high germination potential and vigor, with high physical and genetic purity, characteristics that can be analyzed by multiple tests, following rigorous norms (Marcos-Filho, 2015; FAO, 2013).

The tetrazolium test has stood out among the quality tests adopted by the seed industry, especially for soybeans. This occurs not only because of its accuracy and speed when compared to other tests, but also because of the substantial number of information provided as diagnostic of potential causes for quality reduction (mechanical damage, deterioration due to humidity and bed bug damage) and the possibility of evaluating seed batches' quality and vigor (França Neto, Krzyzanowski, \& Costa, 1998). This test enables to distinguish between vigorous (bright red-carmine colored) and deteriorating (deep red) tissues, and dead or heavily deteriorated tissues (which retain their whitish color) (Deswal \& Chand, 1997), and it has been shown that each type of damage is associated with typical patterns of injury (Figure 1). 


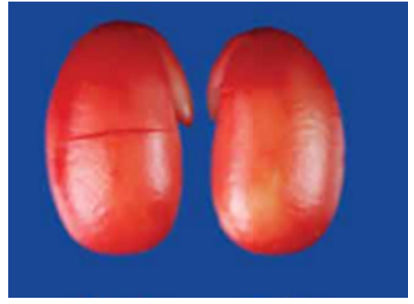

(a) Mechanical damage

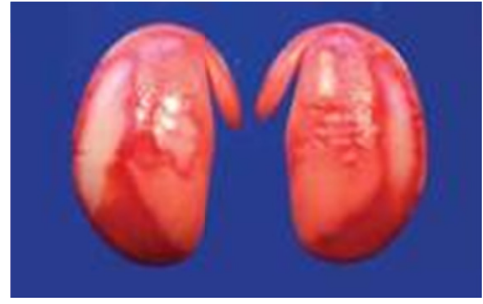

(b) Deterioration by humidity

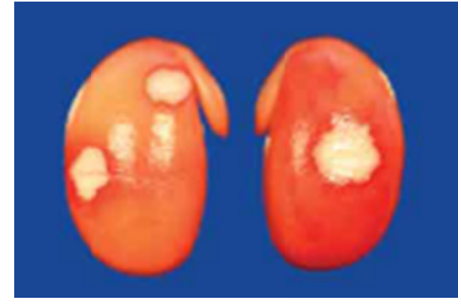

(c) Bed bug damage

Figure 1. Damage patterns found in soybean embryos submitted to the tetrazolium test. Source: França Neto, Krzyzanowski and Costa (1998)

The staining tonality of embryos tissues submitted to tetrazolium test can be used to classify seeds into viable (high and low vigor) and non-viable. Observing such color nuances, combined with the knowledge of seeds characteristics, enables the determination of presence, location, and nature of the damages that can occur in embryonic tissues (Moore, 1973; França Neto, Krzyzanowski, \& Costa, 1998).

Seeds are considered non-viable when contain mechanical damage, sting by bed bug, and deterioration by humidity in regions of apical and root meristem, embryonic axis, along the central cylinder, and in the vascular region (ISTA, 1985).

Although the established criteria are followed (ISTA, 1985; França Neto, Krzyzanowski, \& Costa, 1998), color perception (tetrazolium test, fast green) varies from one individual to another, as well as the criteria of normality/ abnormality seedling and vigor, resulting in greater or less classification rigor. Thus, tools that minimize or eliminate the implied subjectivity in some tests would contribute to the best information credibility and guarantee results, also in addition to reduce the time spent for classification.

Techniques to analyze images are presented as a promising technology due to the improvements in systems of capture, processing, and interpretation of images. The agility in processing plus the reduction of acquisition costs have made the image analysis systems that perform classification and evaluation of agricultural products a more attractive automated way. These techniques allow greater precision in the analysis, intrinsic to the computational processing, besides the extraction of information, which is impossible to be observed (Carvalho, 2010).

Image segmentation is defined as a decomposition process into non-intersecting regions, where a label is assigned to these regions (pixel set), which share some visual characteristics. Most traditional targeting methods are based only on pixel intensity information, but human beings, naturally, use other information when performing segmentation. For this reason, recently, trainable segmentation methods have emerged as an important alternative to improve the accuracy of the areas labeling process (Alekseev, Orlova, Rozaliev, \& Zaboleeva-Zatova, 2014; Arganda-Carreras, Kaynig, Schindelin, Cardona, \& Seung, 2014).

As stated by Cícero and Banzatto-Junior (2003) when using image analysis techniques to characterize seed damage, this promising procedure is possible because each seed is analyzed individually, suggesting in detail not only the damaged areas' analysis but also the location and extent of their damage, with a good degree of accuracy.

In this research field, there are scientific papers in which digital processing and image analysis were used to help improving information and/or image extraction information in seed quality tests.

Corrêa, Cícero, and Abud (2017) have evaluated the cottonseed vigor through computer image analysis and concluded the system is a viable alternative to assess the seed vigor. Pinto, Cicero, França Neto, and Forti (2009) Evaluated mechanical and stink bug damage in soybean seed using x-ray and concluded the technique was effective in detecting the damages studied in soybean seed.

Pereira, Saito, and Bugatti (2016) studied an image analysis framework classification of seed damages and showed that the proposed framework presented notable contributions to the soybean vigor definition process, allowing to automate and accelerate it the process.

Silva, Barros, Albuquerque, Marcos-Filho, Gomes Junior, and Nascimento (2017) evaluated squash seed vigor using computerized image analysis and concluded that system provided data on indexes of seedling vigor and uniformity of seedling development and on seedling growth indicating that automated process a reliable alternative for obtaining consistent information on the physiological potential of seeds. 
Given this context, it is possible to use computational systems based on digital processing and image analysis to help obtaining information from quality tests carried out on the studied seeds.

\section{Methodology}

Tool development and experimental tests were carried out in the Seed and Plant Evaluation Laboratory from UNIOESTE (Western Paraná State University)-Campus Cascavel-PR and in the Teaching Laboratories of Biology and Chemistry from UTFPR (Federal Technological University of Paraná), Campus Santa Helena-PR.

The proposed tool, named SATTz (System of Support for Tetrazolium Test), consists on a base system to classify seeds submitted to the tetrazolium test due to the need for an automation source for this test, to assist the analyst in the decision-making process to classify damages present in soybean embryos samples, and to carry out the test control during the batches' evaluation.

Thus, specific tools were used for each step and, to reduce development cost, open and/or free source technologies were chosen since an open source software is ideal in scientific development, as it can be freely reviewed, modified, and redistributed (Schindelin, Rueden, Riner \& Eliceiri, 2015).

Java object-oriented programming language version 1.8.0_91, in the Integrated Development Environment (Eclipse) version 4.5.2, was applied for this system development. This language was chosen because it is a multiplatform, which allows using and integrating libraries and frameworks for system development and digital image analysis.

The maintenance of data was carried out in the MySQL data file managing system, version 6.3. This system uses a relational database, thus, it was necessary to draw a mapping system of an oriented model to the developed application object for the relational model of MySQL data file. This mapping used Hibernate version 4.3.5, open source framework for object relational mapping, which allows keeping an object-oriented application. Also, that changes on the database do not imply in profound consequences on their application (O'Neil, 2008).

The ImageJ platform is a software distributed freely under GPL (General Public License) and has a dynamic users' community, made up of researchers from several areas of knowledge. Its use allows several applications, ranging from data visualization to advanced image processing and statistical analysis. Due to its extensibility, it attracts biologists and computer scientists who efficiently implement specific image processing algorithms (Schindelin et al., 2015).

Libraries of the FIJI software was used in the process of image analysis, an ImageJ software distribution that adds several functionalities, which make easier scientific image analysis. This software was proposed as a productive collaboration platform between computer science researchers and the research communities on biology (Schindelin et al., 2012).

To perform the image segmentation process, the TWS (Trainable Weka Segmentation) plug-in was used (Arganda-Carreras et al., 2016), which is an integrating part of FIJI software. This plug-in act as a link between the machine learning fields and the digital image processing, providing the framework needed to use and compare the classifiers that make the image segmentation. This combines a collection of machine learning algorithms with a set of image characteristics to produce pixel-based segmentations, by using a set of methods to extract statistical properties from an image based on pixel samples (Arganda-Carreras et al., 2011; Arganda-Carreras et al., 2014). The WEKA (Waikato Environment for Knowledge Analysis) is an open source software consisting of a range of machine learning algorithms destined for data mining, which includes tools for data preprocessing, classification, regression, clustering, rules of association and visualization (Hall et al., 2009). All WEKA classification, regression, and clustering algorithms can be used by TWS (Arganda-Carreras et al., 2014).

In this trial, the classification algorithm based on Random Forest decision trees was used, a classification and regression technique created by Breiman (2001) and composed of a set of decision trees, in which the class prediction for new values is based on a voting system. After the generation of many trees (forest), the class is chosen, based on most tree votes (Breiman, 2001). According to the same author, a Random Forest is a classifier consisting of a set of tree-based classifiers, formally described as $\mathrm{h}\left(\mathrm{x}, \Theta_{\mathrm{k}}\right)$, where $\mathrm{h}$ is the decision tree, $\mathrm{x}$ is the input to be sorted and $\Theta_{\mathrm{k}}$ is the $\mathrm{k}^{-{ }^{\text {th }}}$ identically distributed random vector. Thus, each tree votes in the most popular class for $\mathrm{x}$ input to be classified.

Random Forests are obtained by means of a multi-variant version of a predictor, known as bagging (bootstrapping aggregating) (Breiman, 1996), where the final forecast is performed by the average B predictions (Equation 2) or by taking the majority vote (Equation 1) (Goldstein, Polley, \& Briggs, 2011). 


$$
\hat{\mathrm{f}}_{\text {medium }}(\mathrm{x})=\frac{1}{\mathrm{~T}} \sum_{\mathrm{t}=1}^{\mathrm{T}} \hat{\mathrm{f}}^{\mathrm{t}}(\mathrm{x})
$$

where, $\hat{\mathrm{f}}^{\mathrm{t}}(\mathrm{x})$ : function with the characteristic to be studied; $\mathrm{T}$ : Number of training samples.

$$
\hat{\mathrm{f}}_{\mathrm{bag}}(\mathrm{x})=\frac{1}{\mathrm{~B}} \sum_{\mathrm{b}=1}^{\mathrm{B}} \hat{\mathrm{f}}^{* \mathrm{~b}}(\mathrm{x})
$$

where, $\hat{\mathrm{f}}^{* \mathrm{~b}}(\mathrm{x})$ : function with the characteristic to be studied; $\mathrm{B}$ : Number of bootstrap samples.

The basic algorithm of tree construction is the Classification and Regression Trees (CART) (Breiman, Freadman, Olshen, \& Stone, 1984), which has as particularity the ability to generate high-performance trees, with great capacity of generalization, using as criteria for the best feature selection the Impurity (Equation 3) and GINI (Equation 4) indices (Han, Pei, \& Kamber, 2003). In the forests, the CARTs are expanded to the maximum, without pruning procedure.

$$
\operatorname{Impurity}(\mathrm{N})=-\sum_{\mathrm{i}=1}^{\mathrm{M}} \mathrm{P}\left(\frac{\omega_{\mathrm{i}}}{\mathrm{t}}\right) \log 2 \mathrm{P}\left(\frac{\omega_{\mathrm{i}}}{\mathrm{t}}\right)
$$

where, $\mathrm{N}$ : set examples; M-number of classes; $\omega_{\mathrm{i}}$ : number of examples at $\mathrm{i}^{\text {th }}$ partition; $\mathrm{t}$ : total number of $\mathrm{N}$ set examples.

$$
\operatorname{Gini}(\mathrm{N})=1-\sum_{\mathrm{i}=1}^{\mathrm{M}} \mathrm{P}_{\mathrm{i}}^{2}
$$

where, $\mathrm{P}_{\mathrm{i}}$ : frequency of each class in each knot; $\mathrm{M}$ : number of classes.

The TWS plugin allows the extraction of image characteristics by edge detectors, texture filters, and noise reduction. SATTz extracts the images characteristics using TWS/FIJI core, by HSB color attributes, and delimiting a radius ( 1 to 8 pixels) around each pixel of the image to obtain the histogram of that circle, divided into four parts $(32,64,128,256$ intervals in the histogram). Then, the system calculates the Entropy (Equation 5) of image data. This procedure is paramount in the classifier learning process.

$$
\mathrm{E}=\sum-\operatorname{plog}_{2}(\mathrm{p})
$$

where, p: probability of each histogram part.

The proposed system (Figure 2) is composed of a graphical user interface, which allows, in addition to the training of a classifier through the TWS interface and the printing of the tetrazolium test evaluation card, the registration and manipulation of the data on batches, samples, replications, and seeds.

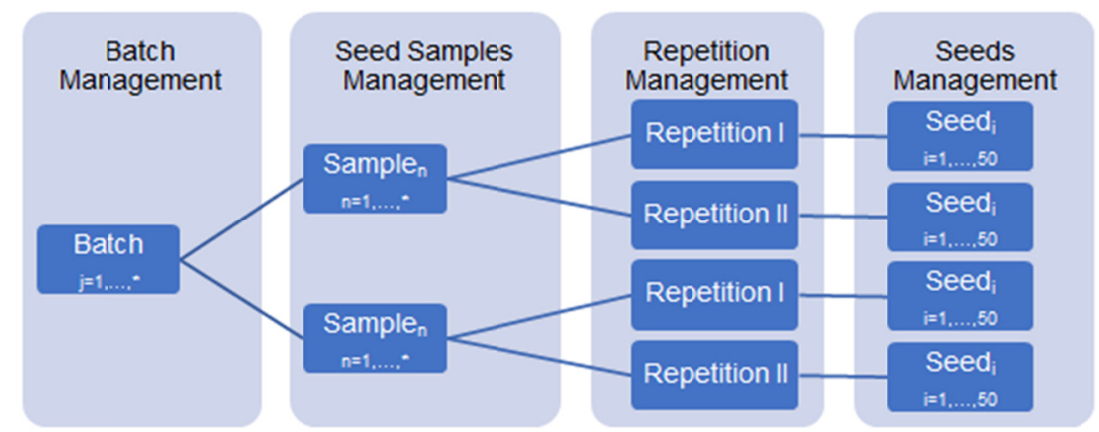

Figure 2. Analytical system management framework

The tetrazolium test was carried out on soybean seeds of cultivars from agricultural properties, as well as seeds known as carriers of specific damages. They were provided by an official seed analysis laboratory in the region. The stock solution at $1.0 \%$ was prepared by mixing $10.0 \mathrm{~g}$ of tetrazolium salt in $1.0 \mathrm{~L}$ distilled water. As suggested by Association of Official Seed Analysts [AOSA] (1983) 100 seeds of each sample were used (two subsamples of 50 seeds each). The seeds were packed in moisture germination paper and kept under these conditions for 16 hours in a BOD (Biochemical Oxygen Demand) type oven at $25{ }^{\circ} \mathrm{C}$. After this period, the seeds were put in plastic bags to receive $0.075 \%$ (Equation 6) tetrazolium solution to stay completely submersed. Afterwards, the temperature was between 35 and $40{ }^{\circ} \mathrm{C}$ for $150-180$ minutes (2.5 to 3 hours) until the staining.

$$
\mathrm{TS}_{0.075 \%}=\mathrm{SS}_{75 \mathrm{ml}}+\mathrm{DW}_{925 \mathrm{ml}}
$$

where, TS: Tetrazolium solution; SS: Stock solution; DW: Distilled water.

After the ideal staining, the seeds were removed from the solution, washed with tap water, and cut longitudinally through the embryonic axis, with a scalpel. The cotyledons were arranged on a blue and squared sheet of EVA 
(Ethyl Vinyl Acetate) (Figure 3). Each cotyledon pair was placed in a rectangle $(2.5 \times 2.8 \mathrm{~cm})$ of pattern. It was necessary to previously train a classification model as the TWS uses supervised classification technique. Thus, embryos samples (in replication images) were selected, representing the major information about damages (bedbug, mechanic, and humidity) and healthy seeds that take part on the test to create a new image, called training image (Figure 3c). It was obtained from the composition of 16 embryos image, selected from the images of repetition I (Figure 3a) and II (Figure 3b) that satisfactorily described the pattern in the tetrazolium test, covering mechanic, humidity, and bedbugs' damages, and healthy seeds.

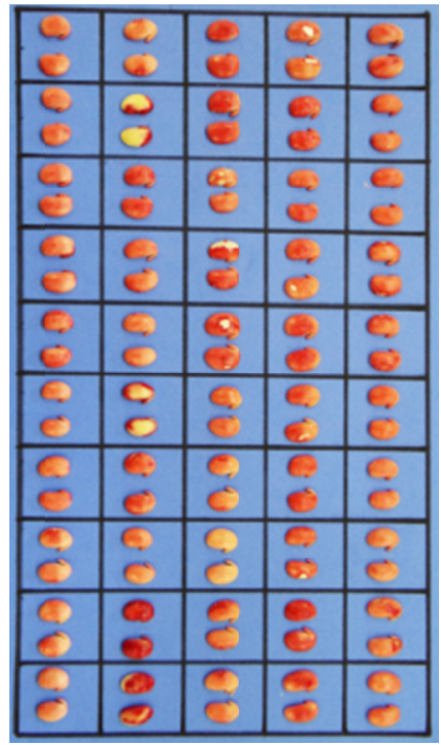

(a) Repetition I

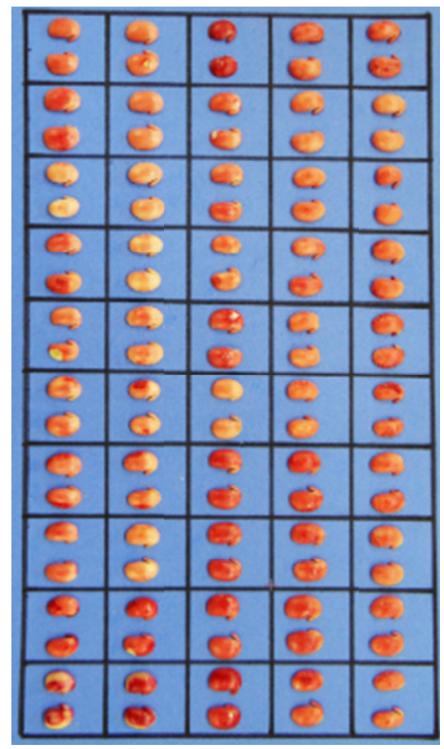

(b) Repetition II

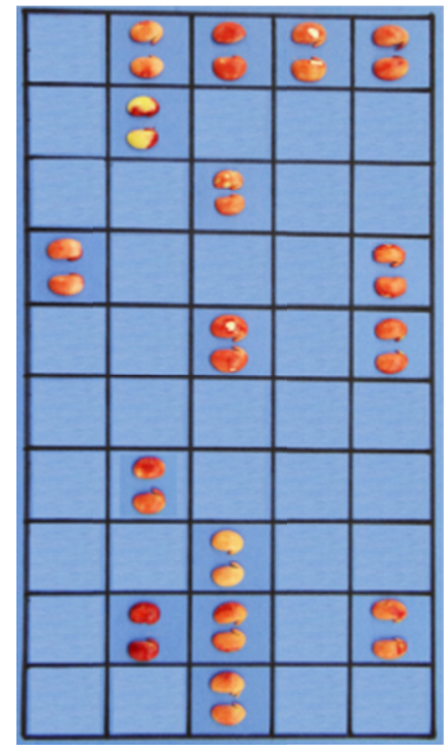

(c) Training

Figure 3. Arrangement of embryos in EVA pattern

The images were obtained using a Sony HX200V 18.2 Mega Pixels camera with Charge-Coupled Device (CMD) Exmor RTM CMOS Sensor, without flash. For the training stage of the classifier, TWS interface (Arganda-Carreras, 2016) was used, allowing characteristics extraction and classifier training for attributes related to the tetrazolium test.

The characteristics of the analyzed images are color in HSB pattern and Entropy with $r_{\max }=8$ and $r_{\min }=1$. The used classifier was the FastRandomForest beginning with 200 trees and two random characteristics per knot. FastRandomForest is a multitasking reimplementation of Random Forest, created by Fran Supek, which optimizes speed and memory usage (Arganda-Carreras, 2016). This process aims to extract the characteristics of images used in the system and the building of decision trees, based on the characteristic vector constructed by the previous process.

\section{Results and Discussion}

The set used has several damages that, in some cases, were found in the same embryos. The regions that presented background patterns were identified in the training image, bed bug damage, deterioration due to humidity damage, and tissue without lesions.

During this process, 39 regions from the bottom class of image (68.236 pixels), 141 regions of the class without damage (48.005 pixels), two regions in mechanic damage class (470 pixels), 59 regions in deterioration due to humidity category (30.354 pixels) and eight regions related to the class of damage per bedbug (2.775 pixels), creating a training data set with 143,291 instances to describe the classes. The training was performed to obtain a classifier pattern and, as a result, the classified training image was obtained (Figure 4). 

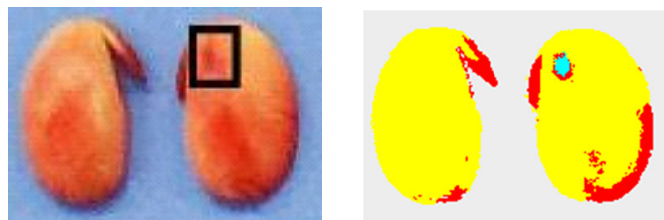

(a) MD
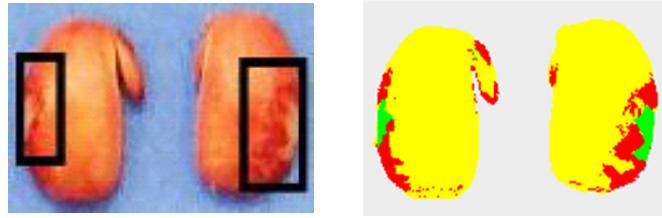

(c) BBD
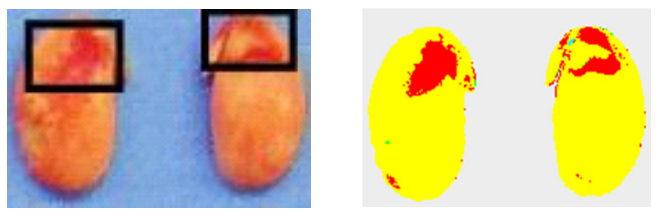

(e) HD
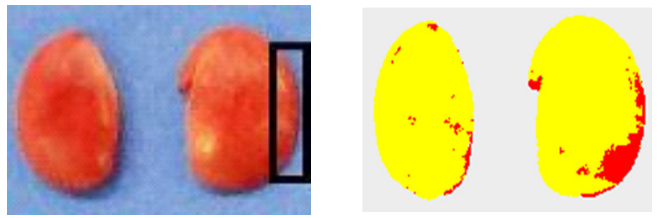

(g) HD
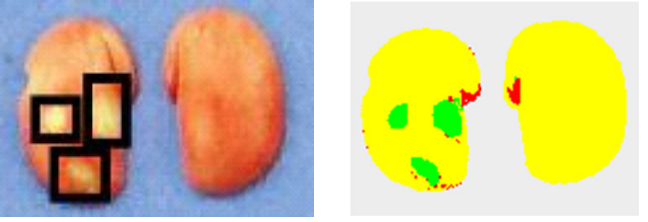

(i) $\mathrm{BBD}$
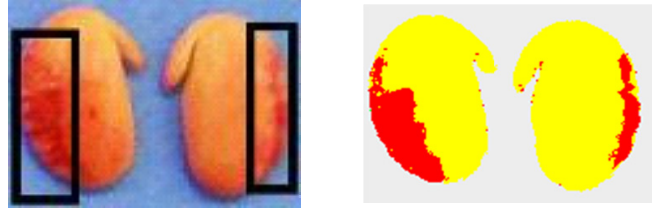

(k) HD
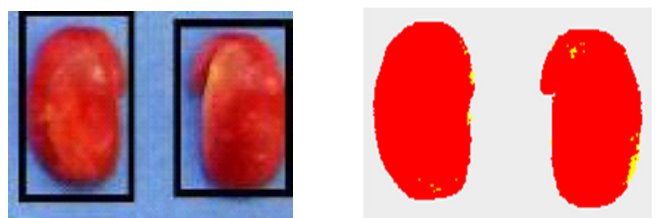

(m) HD
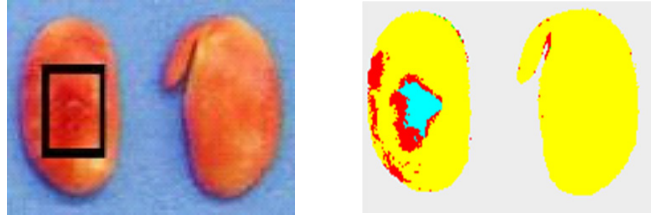

(o) MD
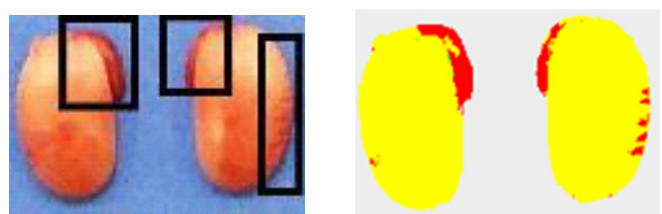

(b) HD
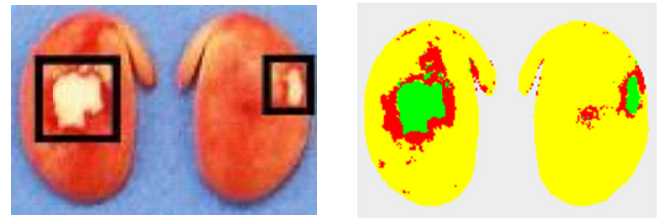

(d) BBD
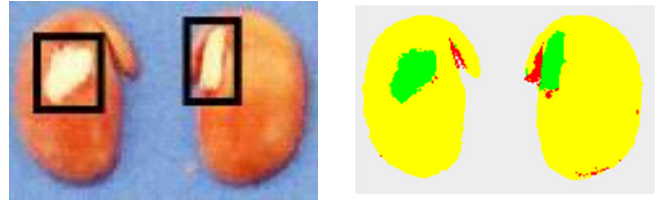

(f) BBD

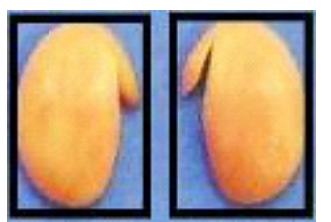

(h) WD
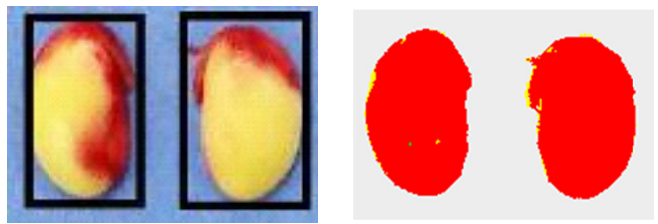

(j) HD
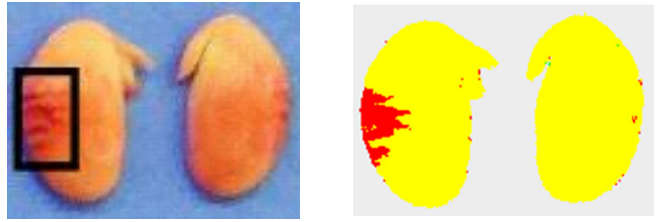

(1) HD
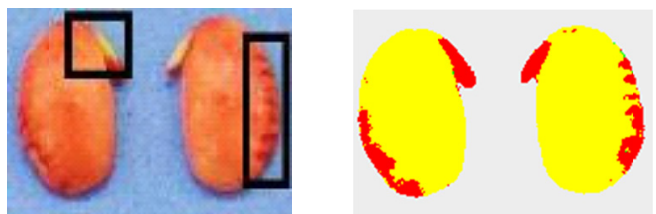

(n) $\mathrm{HD}$

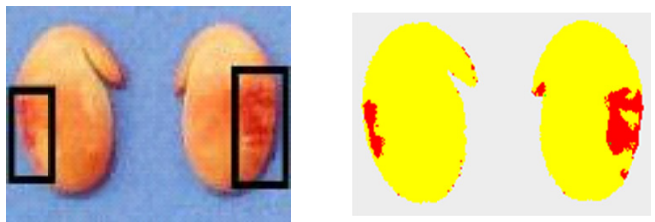

(p) HD

Figure 4. Training images with mechanic damage (MD), humidity deterioration (HD), bedbug damage (BBD), and embryos without damage (WD), with respective segmented images: Grey-background; Red-humidity deterioration; Green-bedbug damage; Blue-mechanic damage; Yellow-vigor tissue 
The registration of batch samples and their replications (consisting of two images of tetrazolium test) were carried out through the batch creation interface, after obtaining the classification pattern that serves as basis for inference in any soybean cotyledons sample. Once the batch was registered with its respective sample, the information was extracted from cotyledons contained in their replications. The replications I and II were analyzed as from the classification interface (Figure 5), using the system individual selection tool in the boundaries where there was a seed cotyledons pair, hence obtaining information about the embryos displayed in the information extraction interface to help on the classification process of the tetrazolium test.

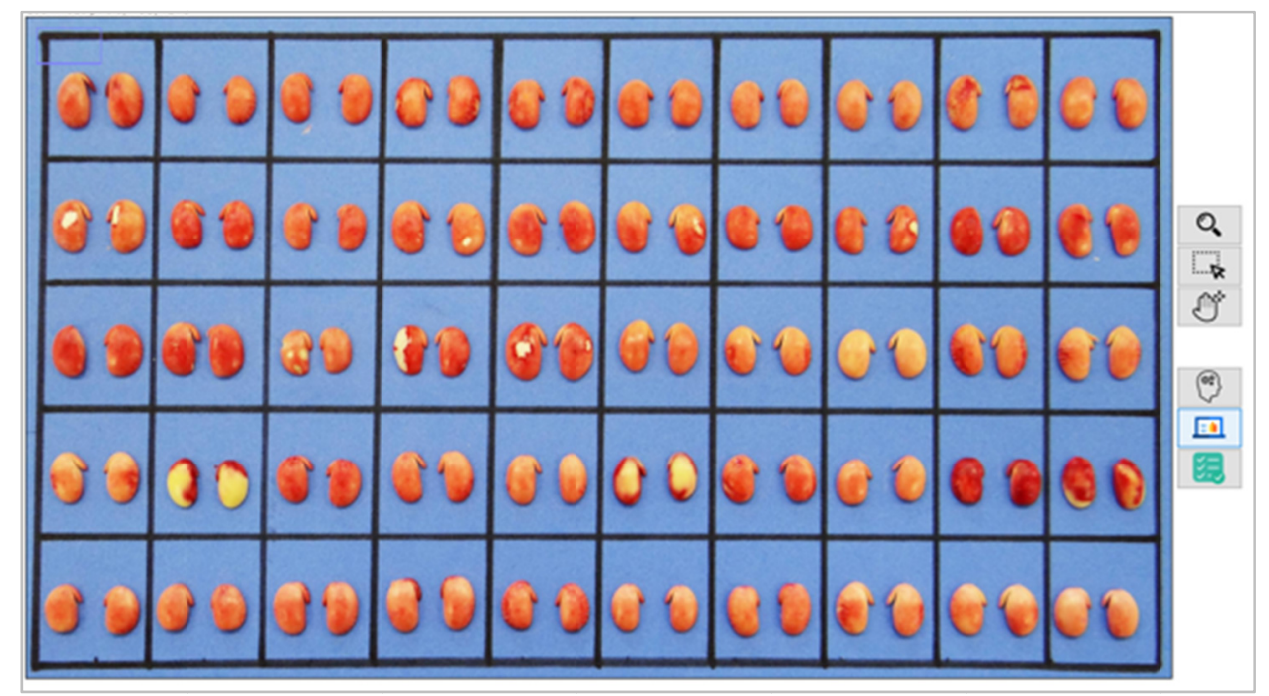

Figure 5. Soybean embryos classification interface

The information extraction interface of embryos (Figure 6) allows the decision-making (vigor (Note 1) class definition to the seed) from the cotyledons image segmented into classes (healthy seed, mechanic damage, bedbug damage, and humidity deterioration) as well as the percentages of pixels classified in these classes. It is also possible to make a visual comparison between segmented and original embryos (Figure 6b) to improve the analyst's inference process or to verify if the classification has been correctly performed.

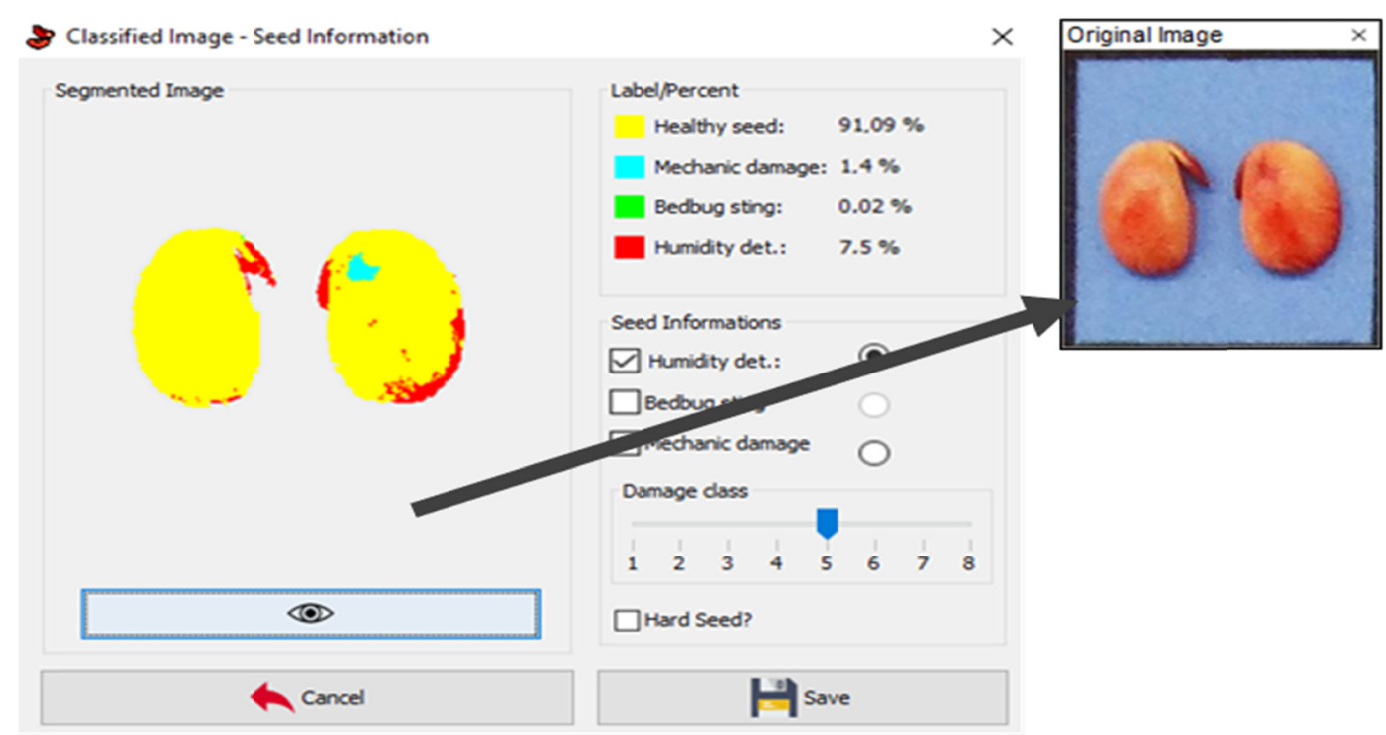

(a) Embryos information

(b) Original image

Figure 6. Embryos information extraction interface 
To improve the predictive properties of the classifier pattern, during the classification process of the 100 seeds in the test, the characteristics extraction was carried out in some images to feed the training set. At the end of the classification process, the data set recorded 230.388 instances (adding 87.097 instances to the initial tests set).

The images labeled by the pattern are shown in Figures $7 \mathrm{a}$ and $7 \mathrm{~b}$, whose percentage of pixels classified as healthy seed was higher than $99.33 \%$ and represented seeds of vigor class 1 . Their external color characteristics are uniform and superficial, indicating slow penetration of the tetrazolium salt (França Neto, Krzyzanowski, \& Costa, 1998).

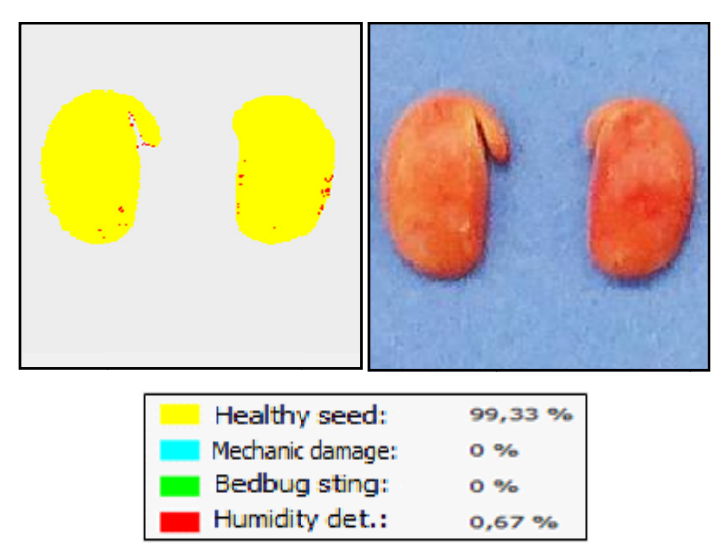

(a) Healthy seeds $(99.33 \%)$

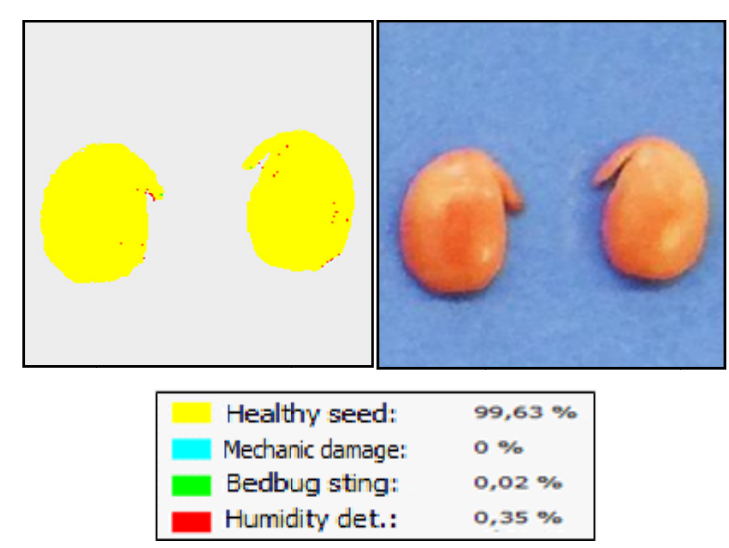

(b) Healthy seeds $(99.62 \%)$

Figure 7. Segmented images classified as without damage

It can be observed that in Figure $7 \mathrm{a}$, the soybean embryos recorded $99.33 \%$ of pixels labeled as healthy seeds and $0.67 \%$ with humidity deterioration. When compared with the original image, there were two small striations of a more intense red color in one of the cotyledons, originating from humidity deterioration. The embryos of Figure $7 \mathrm{~b}$ did not show any deterioration. However, some pixels were classified as belonging to humidity deterioration class $(0.35 \%)$.

The interpretation of humidity deterioration in tetrazolium test can be described by some patterns, such as striations (evidenced by the test in dark red carmine), caused by compression of integument on cotyledons as a function of expansion (hydration) and contraction (dehydration) cycles, whose results are wrinkles in integument and lesion in cotyledons. This kind of pattern may be found in embryonic axis and cotyledons.

Areas of more intense red or milky white staining are also characteristic patterns of this deterioration. Mostly, they are a result of small striations increase and cause a greater damage (França Neto, Krzyzanowski, \& Costa, 1998).

It can also be seen in Figures $8 \mathrm{a}$ and $8 \mathrm{~b}$ images whose most apparent characteristics, labeled by the classifier pattern, are those that give to pixel humidity deterioration patterns. 


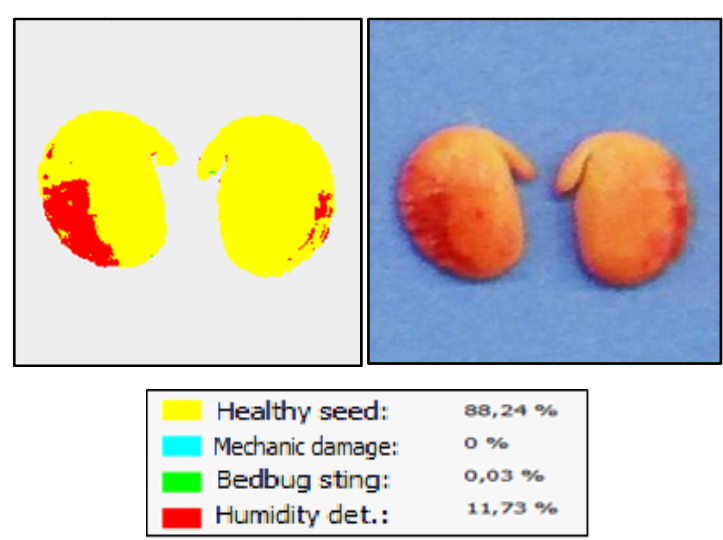

(a) Humidity deterioration on the opposite region to embryonic axis

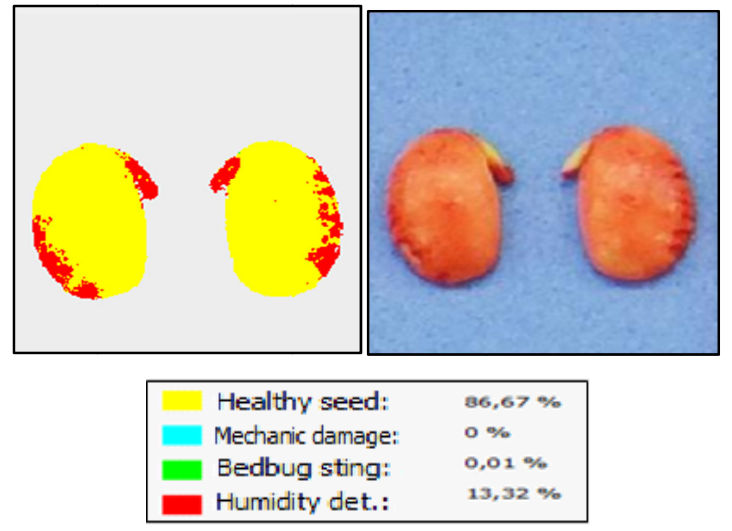

(b) Humidity deterioration on embryonic axis

Figure 8. Segmented images with humidity deterioration characteristics

In Figures $8 \mathrm{a}$, it is possible to observe the number of pixels classified as humidity deterioration in cotyledons, clustered in the opposite region to embryonic axis. In the non-segmented image, striations and bands can be seen in these regions, characteristics of humidity deterioration.

In Figures 8b, it is observed that the embryonic axis also presented pixels classified in this way. When compared with the original image (without damage), it is possible to observe, both in the cotyledons and embryonic axis, striations and bands in darker red carmine color and whitish parts (dead tissue), which are aspects of humidity deterioration. When looking at images set that presented humidity deterioration, it is observed that the segmentation generated by the system corroborates with the real location and extension of damage in the original images.

The mechanic damage result from impacts, cuts, and abrasions arising from the harvesting, trail, transport, and processing process identified in the tetrazolium test presents characteristic patterns such as cracks and abrasions. When recent, they are colored in dark red carmine, or white in case they have not been recently identified, both in cotyledons as in embryonic axis (Bewley \& Black, 1994; França Neto, Krzyzanowski, \& Costa, 1998). Characteristic embryos with this kind of damage are presented in Figures 9a to $9 b$.

Pixels classified as mechanic damage can be observed in one cotyledon (Figure 9a), in the vascular region adjacent to the attachment point. There has been recorded humidity deterioration in cotyledons in embryonic axis and its opposite region; on the other hand, it is not distributed throughout its length. It can be seen, in the original image, that the mechanic damage came from an abrasion in seed.

In Figure $9 \mathrm{~b}$ some pixels classified as mechanic damage can be seen in the region just above half of the embryos (vascular region), plus a substantial extent of deterioration due to humidity distributed between the cotyledons. And when analyzed the original image, it was recorded that mechanic damage is due to seeds kneading that happened during some of the production processes, and that the seed also has deterioration patterns due to humidity in its cotyledons.

In general, pixels with this pattern of damage were well identified and classified. 


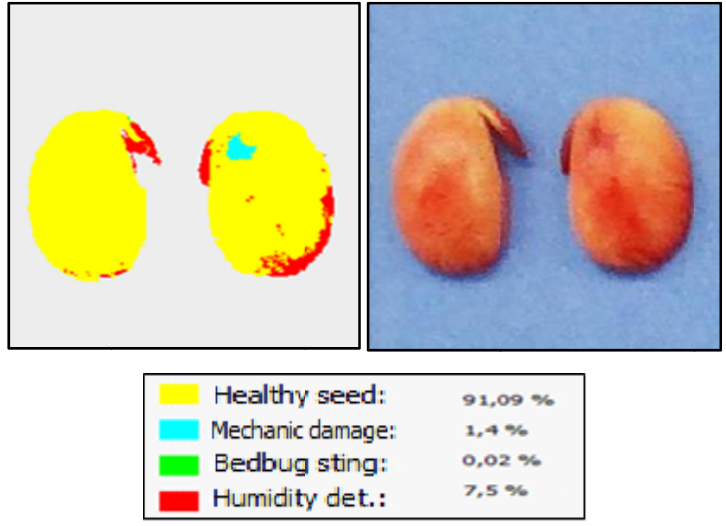

(a) Mechanic damage in vascular region

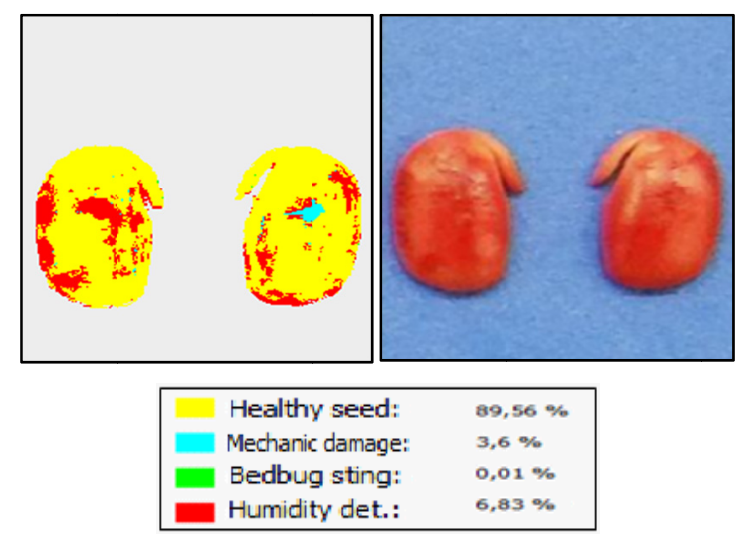

(b) Mechanic damage in central portion

Figure 9. Segmented images with mechanic damage characteristics

The damage caused by bedbug sting is easily identified by typical lesions, with circular patterns and whitish or yellowish color, as well as an intense red carmine ring around it (França Neto, Krzyzanowski, \& Costa, 1998). The embryos that were segmented with this characteristic pattern are shown in Figures 10a and 10b.

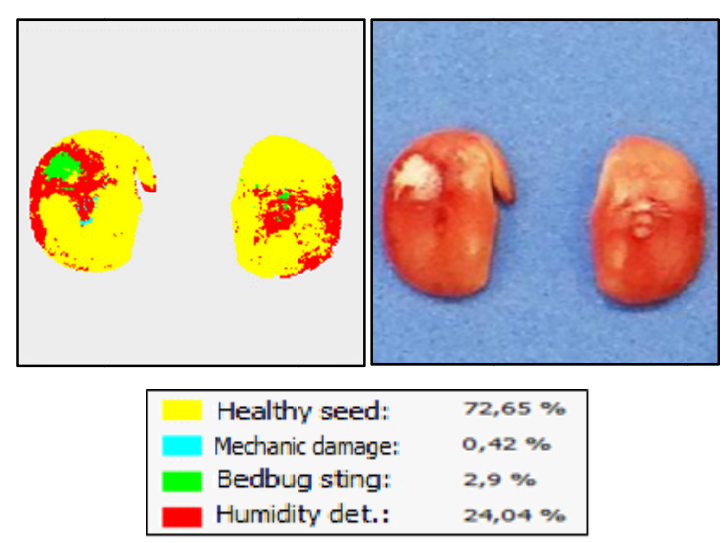

(a) Sting bedbug in vascular region

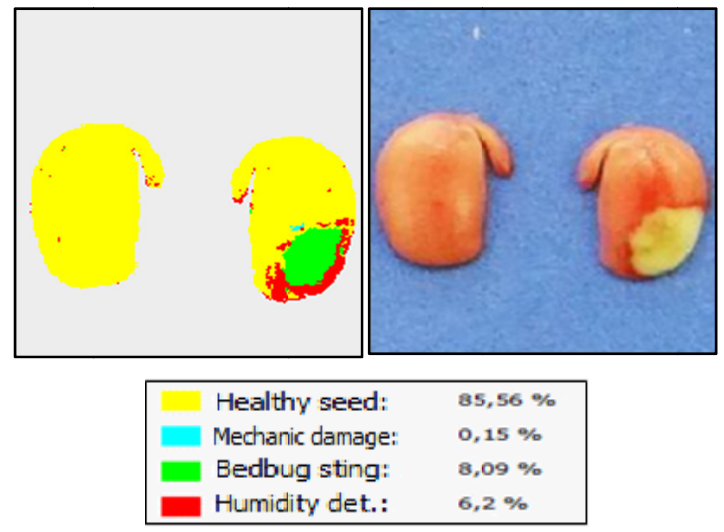

(b) Sting bedbug below vascular region

Figure 10. Segmented images with bedbug sting characteristics

Pixels classified as bedbug damage are found in cotyledons, as observed in Figure 10a. They are in the superior part of the soybean embryo in a cotyledon and a small part in the central position of the other cotyledon. Pixels observed around this damage are also classified as humidity deterioration. Pixels classified as bedbug damage reach a non-vascularized region of cotyledons, as can be observed in Figure 10b, in the region opposite to the embryonic axis. It is possible to observe that pixels were correctly classified by the visual analysis from the original images of these segmentations, both for bedbug damage and humidity deterioration. Even though in some cases the red ring around the damage was identified as a deterioration pattern by humidity.

After the embryos were classified, the results interface of the tetrazolium test was generated by the reporting interface. This data sheet is based on the tetrazolium test data file (França Neto, Krzyzanowski, \& Costa, 1998). The system generates this data file automatically, considering the previous classification, in which viability and vigor percentages are registered. It also identifies and quantifies the kinds of damages, as well as highlights the most apparent ones.

After selecting the batch and sample, the system generates a Portable Document Format (PDF) file with the test results (Figure 11). 


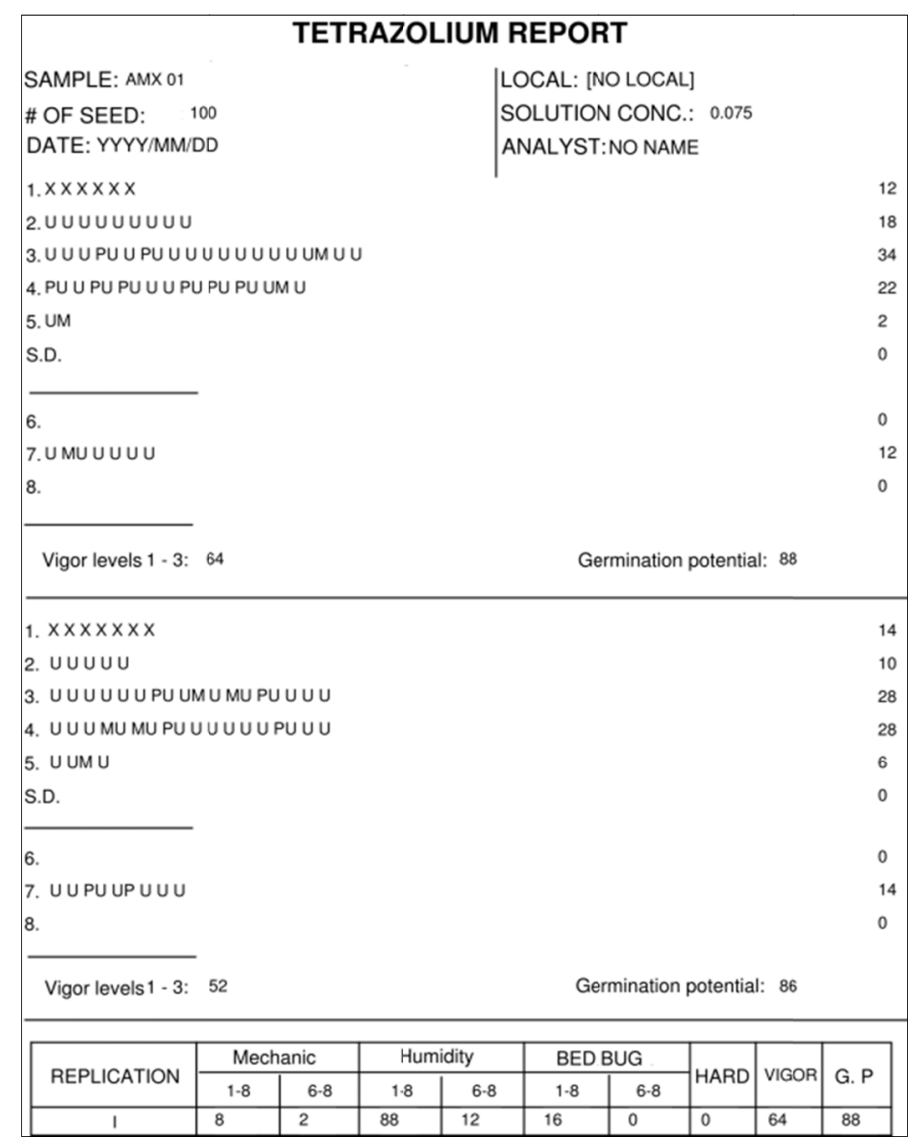

Figure 11. Tetrazolium test report

The report determines the percentage of seeds, classified in each viability class, and the software calculates germination potential up from the sum of estimated values in the classes from 1 to 5 , and the vigor is obtained by the sum of the levels from 1 to 3, following what França Neto, Krzyzanowski, and Costa (1998) have established.

\section{Conclusion}

Concerning the developed software, it can be concluded it presents an alternative to performing a less subjective seeds classification for tetrazolium test, since percentages extraction of classified pixels for damage classes by the segmented images provides valuable information in the decision making. Moreover, Automated generation of tetrazolium test report from the classified samples saves time in the extracting process of test information and shows itself as a potential automation tool in research and commercial environments.

\section{Acknowledgements}

Authors are thankful to Western Paraná State University, Federal University of Technology-Paraná and Coordination for the Improvement of Higher Education Personnel/Araucária Foundation (CAPES/FA) for supporting this research.

\section{References}

Alekseev, A. V., Orlova, Y. A., Rozaliev, V. L., \& Zaboleeva-Zotova, A. V. (2014). Two-Stage Segmentation Method for Context-Sensitive Image Analysis (pp. 331-340). Paper presented at the eleventh Joint Conference JCKBSE, Volgograd, Russia. https://doi.org/10.1007/978-3-319-11854-3_28

Arganda-Carreras, I., Cardona, A., Kaynig, V., Rueden, C., \& Schindelin, J. (2011). Trainable WEKA segmentation. Retrieved from https://imagej.net/Trainable_Weka_Segmentation

Arganda-Carreras, I., Kaynig, V., Rueden, C., Schindelin, J., Cardona, A., \& Seung, H. S. (2016) Trainable_Segmentation: Release v3.1.2 Retrieved from https://zenodo.org/record/59290\#.XO6-cohKiUk 
Arganda-Carreras, I., Kaynig, V., Schindelin, J., Cardona A. H., \& Seung, S. (2014), Trainable Weka Segmentation: A machine learning tool for microscopy image segmentation. Retrieved from http://bit.do/eTHEL

Association of Official Seed Analysts. (2008). Seed vigor testing handbook. East Lansing: AOSA.

Bewley J. D., \& Black M. (1994). Seeds. Physiology of development and germination (2nd ed). New York, NY: Plenum Press. https://doi.org/10.1007/978-1-4899-1002-8

Breiman, L. (1996). Bagging predictors. Machine Learning, 24(2), 123-140. https://doi.org/10.1023/A:101805 4314350

Breiman, L. (2001). Random forests. Machine Learning, 45(1), 5-32. https://doi.org/10.1023/A:1010933404324

Breiman, L., Freadman, J., Olshen, R., \& Stone, C. (1984). Classification and regression trees. Grove, CA: Wadsworth International.

Carvalho, M. L. M. (2010). Utilização da análise de imagem-conceitos, metodologias e usos. Informativo ABRATES, 20(3), 45-47.

Cícero, S. M., Banzatto-Junior, H. L. (2003). Avaliação do relacionamento entre danos mecânicos e vigor, em sementes de milho, por meio da análise de imagens. Revista Brasileira de Sementes, 25(1), 29-36. https://doi.org/10.1590/S0101-31222003000100006

Corrêa, P. D., Cicero, S. M., \& Abud, H. F. (2019). Evaluation cottonseed vigor through computer image analysis of the seedlings. Journal of Seed Science, 41(1), 54-59. https://doi.org/10.1590/2317-1545 v41n1200649

Dall'Gnol, A. (2000). The impact of soybeans on the Brazilian economy. Technical information for agriculture. São Paulo: Máquinas Agrícolas Jacto.

Deswal, D. P., \& Chand, U. (1997). Standardization of thetetrazolium test for viability estimation in rice bean (Vigna umbellata (Thunb.) Ohwi \& Ohashi) seeds. Seed Science and Technology, 25(3), 409-417.

FAO (Food and Agriculture Organization of the United Nations). (2010). Seeds in emergencies: A technical handbook. FAO Plant Production and Protection Paper 202. FAO, Rome, Italy.

França Neto, J. B., Krzyzanowski, F. C., \& Costa, N. P. da. (1998). The tetrazolium test for soybean seeds. Londrina, PR: EMBRAPA-CNPSo.

Goldstein, B. A., Polley, E. C., \& Briggs, F. B. (2011). Random forests for genetic association studies. Statistical Applications in Genetics and Molecular Biology, 10(1), 32. https://doi.org/10.2202/1544-6115.1691

Hall, M., Frank, E., Holmes, G., Pfahringer, B., Reutemann, P., \& Witten, I. H. (2009). The WEKA data mining software: An update. ACM SIGKDD Explorations Newsletter, 11(1), 10-18. https://doi.org/10.1145/ 1656274.1656278

Han, J., Pei, J., \& Kamber, M. (2011). Data mining: Concepts and techniques. Waltham, MA: Elsevier.

ISTA (International Seed Testing Association). (1985). International rules for seed testing. Seed Science and Technology, 13, 229-526.

Marcos-Filho, J. (2015). Seed vigor testing: an overview of the past, present and future perspective. Scientia Agricola, 72(4), 363-374. https://dx.doi.org/10.1590/0103-9016-2015-0007

Moore, R. P. (1973). Tetrazolium staining for assessing seed quality. In W. Heydecker (Ed.), Seed ecology (pp. 347-366). London, Butterworth.

O'Neil, E. J. (2008). Object/relational mapping 2008: Hibernate and the entity data model. Paper presented at ACM SIGMOD international conference on management of data (pp. 1351-1356). ACM, New York. https://doi.org/10.1145/1376616.1376773

Pereira, D. F., Saito, P. T. M., \& Bugatti, P. H. (2016). An image analysis framework for effective classification of seed damages (pp. 61-66). Paper presented at the 31st Annual ACM Symposium on Applied Computing. ACM, New York, NY. https://doi.org/10.1145/2851613.2851637

Pinto, T. L. F., Cicero, S. M., França Neto, J. B., \& Forti, V. A. (2009). An assessment of mechanical and stink bug damage in soybean seed using X-ray analysis test. Seed Science and Technology, 37(1), 110-220. https://doi.org/10.15258/sst.2009.37.1.13 
Roessing, A. C., Dall'Agnol, A., Lazzarotto, J. J., Hirakuri, M. H., \& Oliveira, A. B. (2007). O complexo agroindustrial da soja brasileira. Circular Técnica, 43.

Schindelin J., Arganda-Carreras I., Frise, E., Kaynig, V., Longair, M., Pietzsch, T., ... Cardona A. (2012). Fiji: An open-source platform for biological-image analysis. Nature Methods, 9(7), 676-682. https://doi.org/ 10.1038/nmeth.2019

Schindelin, J., Rueden, C. T., Hiner, M. C., Eliceiri, K. W. (2015). The ImageJ ecosystem: An open platform for biomedical image analysis. Molecular Reproduction and Development, 82(7), 518-529. https://doi.org/ $10.1002 / \mathrm{mrd} .22489$

Silva, P. P., Barros, A. C. S. A., Marcos-Filho, J., Gomes Junior, F. G., \& Nascimento, W. M. (2017). Assessment of squash seed vigor using computerized image analysis. Journal of Seed Science, 39(2), 159-165. https://dx.doi.org/10.1590/2317-1545v39n2171177

\section{Notes}

Note 1 . The assignments of seed vigor classifications based on the information extracted by the system were according to the methodology of tetrazolium test for soybean seeds (França Neto, Krzyzanowski, \& Costa, 1998).

\section{Copyrights}

Copyright for this article is retained by the author(s), with first publication rights granted to the journal.

This is an open-access article distributed under the terms and conditions of the Creative Commons Attribution license (http://creativecommons.org/licenses/by/4.0/). 